\title{
Antioxidant Effect of Epigallocatechin-3-Gallate in a Bleomycin-Induced Scleroderma Model
}

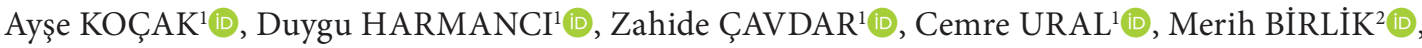 \\ Sülen SARIOĞLU ${ }^{3}$, Osman YILMAZ ${ }^{4}$ (i), Gül GÜNER AKDOĞAN ${ }^{5}$ (D) \\ ${ }^{1}$ Department of Molecular Medicine, Dokuz Eylül University, Institute of Health Sciences, İzmir, Turkey \\ ${ }^{2}$ Department of Rheumatology, Dokuz Eylül University, Faculty of Medicine, İmir, Turkey \\ ${ }^{3}$ Department of Pathology, Dokuz Eylül University, Faculty of Medicine, İzmir, Turkey \\ ${ }^{4}$ Department of Laboratory Animal Sciences, Dokuz Eylül University, Institute of Health Sciences, Izmir, Turkey \\ ${ }^{5}$ Department of Medical Biochemistry, İzmir University of Economics, Medical Faculty, İzmir, Turkey
}

\begin{abstract}
Objectives: This study aims to evaluate the antioxidant effects of epigallocatechin-3-gallate (EGCG) in a bleomycin (BLM)-induced scleroderma model.

Materials and methods: Thirty-two healthy female Balb-c mice (6-8-week-old; weighing $22 \pm 5 \mathrm{~g})$ were used in this study. The mice were randomly divided into four groups: control $(n=8), B L M(n=8), B L M+E G C G(n=8)$, and EGCG $(n=8)$. Skin tissue specimens were collected at the end of the experiments. Histopathological examinations of skin tissues were performed. Skin samples were assessed for total superoxide dismutase (SOD) activity and malondialdehyde (MDA) content. The phosphorylation of p-38 mitogen-activated protein kinase and Akt protein (the serine-threonine protein kinase encoded by the AKT), as well as the nuclear factor-kappa B (NF-kB) levels, were analyzed by western blotting.

Results: Epigallocatechin-3-gallate-treated groups were observed to have reduced connective tissue fibrosis in the dermis area using Masson's trichrome staining method. Pp-38 and NF-KB were found to decrease significantly in the BLM + EGCG group compared with the BLM group. Parallel to these findings, phosphorylated Akt protein was found to increase in the BLM + EGCG group compared with the BLM group. SOD activity was increased in the EGCG group and content of MDA level was decreased in EGCG groups.

Conclusion: The results of the present study demonstrated that EGCG represses pp-38 and NF- $\mathrm{kB}$ signaling pathways, exerting a protective effect for scleroderma through its anti-oxidative role.

Keywords: Antioxidant effect; fibrosis; oxidative stress; scleroderma.
\end{abstract}

Systemic sclerosis or scleroderma (SSc) is an autoimmune connective tissue disease. ${ }^{1}$ $\mathrm{SSc}$ is characterized by fibrosis of skin and internal organs. The cause of SSc is unknown and pathogenesis is unclear; it is characterized by overproduction of excessive extracellular matrix (ECM). ${ }^{2}$ In this disease, normal tissue architecture is broken and replaced with collagenrich, stiff connective tissue. ${ }^{3}$ Also, $\mathrm{SSc}$ is a very rare disease in the population and shows three pathological features: injuries to vascular endothelial cells, imbalanced immune system, and ECM accumulation. ${ }^{1}$ As in other autoimmune diseases, females are at higher risk than males. ${ }^{3-5}$ In this disease, oxidative stress may play a role for pathogenesis. ${ }^{6-8}$ Recent studies showed a relationship between oxidative/antioxidative markers and SSc. ${ }^{9-12}$

Received: January 12, 2018 Accepted: February 20, 2018 Published online: May 07, 2018

Correspondence: Ayşe Koçak, PhD. Dokuz Eylül Üniversitesi Sağlık Bilimleri Enstitüsü, Moleküler Tıp Anabilim Dalı, 35330 Balçova, İzmir, Turkey. Tel: +90 507 - 2243706 e-mail:kocak.ayse@gmail.com 
Animal models are used to provide clues and therapeutic interventions for human diseases. Bleomycin (BLM) is often used as an antitumor agent for several cancer types and is originally isolated from the fungus Streptomyces verticillus. ${ }^{13}$ Recent studies showed that BLM upregulates collagen messenger ribonucleic acid expression in human lung or dermal fibroblasts in vivo models like a normal SSc phenotype. ${ }^{14,15}$ Yamamoto et al. ${ }^{16-21}$ established a mice model for SSc by local treatment by BLM subcutaneous (sc) injections during 21 days. ${ }^{16-21}$ Concerning the in vivo research, the BLM-induced experimental $\mathrm{SSc}$ mouse is the most used model for studying $\mathrm{SSc}^{22}$

Overproduction of reactive oxygen species (ROS) is known to induce tissue damage and cell death, which could lead to several physiological and pathological processes. Studies have shown that ROS generation occurs in fibrosis. ROS, such as superoxide anions, hydrogen peroxides, and hydroxyl radicals have been demonstrated to be an important mediator of BLM-induced fibrosis. ${ }^{23-25}$ In SSc, tumor necrosis factor alpha (TNF- $\alpha$ ) signaling increases fibroblast proliferation, collagen synthesis and ROS production. ${ }^{26,27}$ This situation also leads to suppress the expression of antioxidant enzymes such as superoxide dismutase (SOD). ${ }^{27}$ The accumulation of matrix proteins is increased by both TNF- $\alpha$ signaling and ROS production. ${ }^{27}$ Besides, there are studies showing that free radicals cause immune system activation and cytokine production and stimulate extracellular matrix elements and the amount of collagen. ${ }^{28-30}$

There are two types of antioxidant systems in human metabolism. The first one is the enzymatic antioxidant system, including SOD, glutathione peroxidase, and catalase enzymes. The second is the nonenzymatic antioxidant system, including carotenoids, vitamin $\mathrm{E}$, vitamin $\mathrm{C}$, thiol, and glutathione. Malondialdehyde (MDA) is a lipid peroxidation marker for oxidative stress.

Epigallocatechin-3-gallate (EGCG), the most abundant catechin, is the major effective component of green tea and has been shown to have beneficial health effects on skin. ${ }^{31,32}$ In liver fibrosis, EGCG was shown to inhibit proliferation of fibroblasts, reducing collagen deposition, and upregulating the mitochondrial respiratory chain. ${ }^{33}$ EGCG has been shown to play protective role against breast cancer ${ }^{34-36}$ colon and prostate cancer. ${ }^{37}$ Besides, it has been promising as a source of new molecular therapies. The possible role of EGCG in oxidative stress has attracted attention over the last few years. However, the role of EGCG on SSc focusing on the pathways involving oxidative stress has not been investigated. In this study, we aimed to evaluate the antioxidant effects of EGCG in a BLM-induced SSc model.

\section{MATERIALS AND METHODS}

Experiments were performed on dermal tissues obtained from previous study with approval of the Animal Care and Use Committee of the Dokuz Eylul University (Protocol No: 79/2012). This study was conducted at Dokuz Eylul University between April 2015 and May 2015. Skin fibrosis was induced in 32 pathogen-free female Balb/c mice (6-8-week-old; weighing 20-22 g) (Dokuz Eylul University, Department of Experimental Animals) by local injection of BLM for 21 days. ${ }^{16,20,38}$ The animals were kept under standard animal laboratory conditions: temperature of $20-22^{\circ} \mathrm{C}$, humidity of $55-60 \%$, photoperiod of $12: 12$ hour light: dark cycle. They had free access to standard laboratory feed and water, according to the study protocol. All methods including the euthanasia procedure were conducted in accordance with Guide for Care and Use of Laboratory Animals, Institute for Laboratory Animal Research, National Institute of Health (NIH). The study protocol was reviewed and approved by Dokuz Eylul University Ethics Committee for Animal Research (Protocol No: $1 / 2018$ ).

Bleomycin was used for SSc model (Onko Koçsel, İstanbul, Turkey). EGCG (Sigma-Aldrich, Dorset, UK) solution was prepared as $20 \mathrm{mg} / \mathrm{kg}$ in saline as reported earlier. ${ }^{39}$ The mice were randomly divided into four groups of eight animals each, as follows:

1. Control group was given $100 \mu \mathrm{L}(100 \mu \mathrm{g})$ sc saline (SF) once a day, $100 \mu \mathrm{L}(100 \mu \mathrm{g})$ intraperitoneal (ip) SF twice a week,

2. BLM group was given $100 \mu \mathrm{L}(100 \mu \mathrm{g}) \mathrm{sc}$ BLM once a day, $100 \mu \mathrm{L}(100 \mu \mathrm{g})$ ip SF twice a week, 
3. BLM + EGCG group was given $100 \mu \mathrm{L}$ $(100 \mu \mathrm{g})$ sc BLM once a day, $100 \mu \mathrm{L}$ $(100 \mu \mathrm{g})$ ip EGCG twice a week,

4. EGCG group was given $100 \mu \mathrm{L}(100 \mu \mathrm{g}) \mathrm{sc}$ SF once a day, $100 \mu \mathrm{L}(100 \mu \mathrm{g})$ ip ECCG twice a week.

After 21 days, the animals were sacrificed under ether anesthesia in sterile condition. The injected skin section was removed and processed for analysis.

The injected sections of mice skin were fixed in $4 \%$ formalin and embedded in paraffin. Four micrometer $(\mu \mathrm{m})$ sections were stained with Masson's trichrome. Dermal thicknesses of the injected sections were analyzed with Nikon Eclipse C1 microscope (Nikon, Tokyo, Japan) at 200-fold magnification and digitalized by Nikon DS-Fi2 camera. Dermal sections were measured (as $\mu \mathrm{m}$ ) on 10 areas. In each series of experiments, the dermal thicknesses were evaluated statistically.

All dermal tissues were stored at $-80^{\circ} \mathrm{C}$ before the experiment. Dermal tissues were washed with cold phosphate buffer solution and homogenized using a TissueLyser (Qiagen, Hilden, Germany) in $50 \mathrm{mM}$ potassium phosphate buffer $\mathrm{pH}: 7.8$, containing $0.5 \mathrm{mmol} / \mathrm{L}$ phenylmethylsulfonyl fluoride, $10 \mu \mathrm{g} / \mathrm{mL}$ aprotinin, and centrifuged at $2500 \mathrm{~g}$ for MDA analysis.

The protein content in each tissue was determined using the bicinchoninic acid protein assay (Thermo Pierce, Rockford IL, USA). Bovine serum albumin was used as a standard.

The MDA assay was based on the condensation of one molecule of MDA with two molecules of thiobarbituric acid (TBA) in the presence of reduced agents. The TBA + MDA complex was analyzed by high-performance liquid chromatography system. The MDA levels were expressed as $\mu \mathrm{mol} / \mathrm{g}$ protein.

For the SOD assay, homogenates were centrifuged at $11000 \times \mathrm{g}$ for 10 minutes. The supernatant was used for determination of SOD enzyme activity. SOD activity was analyzed by spectrophotometric assay kit (Cayman Chemical Company, Inc., Ann Arbor, MI, USA) and performed according to the manufacturer's instructions. This assay utilizes a tetrazolium salt for the detection of superoxide radicals generated by xanthine oxidase and hypoxanthine. The reaction was monitored at $440 \mathrm{~nm}$ using a plate reader (Synergy HT, BioTek Instrument Inc., Winooski, USA). One unit $(\mathrm{U})$ of SOD is defined as the amount of enzyme needed to exhibit 50\% dismutation of the superoxide radical. SOD activity data were expressed as $\mathrm{U} / \mathrm{mg}$ protein.

The protein concentration was quantified using a bicinchoninic acid protein assay kit (Thermo Pierce, Rockford IL, USA). A total of $25 \mu \mathrm{g}$ of protein was separated by sodium dodecyl sulphatepolyacrylamide gel electrophoresis and transferred to a $0.45 \mu \mathrm{m}$ pore size, polyvinylidene difluoride membrane (Millipore, Bedford, USA) which was then blocked for one hour at room temperature using 5\% skim milk/tris-buffered saline with tween (TBST). The blots were incubated overnight with a 1:1,000 dilution of appropriate primary antibody in 5\% skim milk/TBST. The following antibodies were used: Rabbit pp-38, p-38, Akt (the serine-threonine protein kinase encoded by the AKT), phosphorylated Akt (p-Akt), nuclear factor-kappa B (NF-kB) (Cell Signaling Technology Inc., Danvers, MA, USA). After the primary incubation, membranes were washed with TBST, the blots were incubated with the appropriate horseradish peroxidaseconjugated mouse anti-rabbit secondary antibody (Cell Signaling Technology Inc., Danvers, MA, USA). As a control for equal protein loading, membranes were stripped and re-incubated for $\beta$-actin using a monoclonal antibody (Santa Cruz Biotecnology Inc, CA, USA). Protein bands were visualized using enhanced chemiluminescence (Millipore, Bedford, USA) and were quantitated using Image-J, NIH image densitometry software. Relative expressions of proteins were calculated using the ratios: NF- $\kappa \mathrm{B} / \beta$-actin, $\mathrm{p}$-Akt/Akt, $\mathrm{pp}-38 / \mathrm{p}-38$. All experiments were performed in triplicate and the western blotting images were presented as the representative of three images.

\section{Statistical analysis}

All experimental data are presented as the mean \pm standard deviation. The data were analyzed using Student's t-test and differences between multiple groups were evaluated by twoway analysis of variance. Statistical analyses were performed with IBM SPSS version 22.0 software (IMB Corp., Armonk, NY, USA). $\mathrm{P}<0.05$ was considered to indicate a statistically significant difference. 

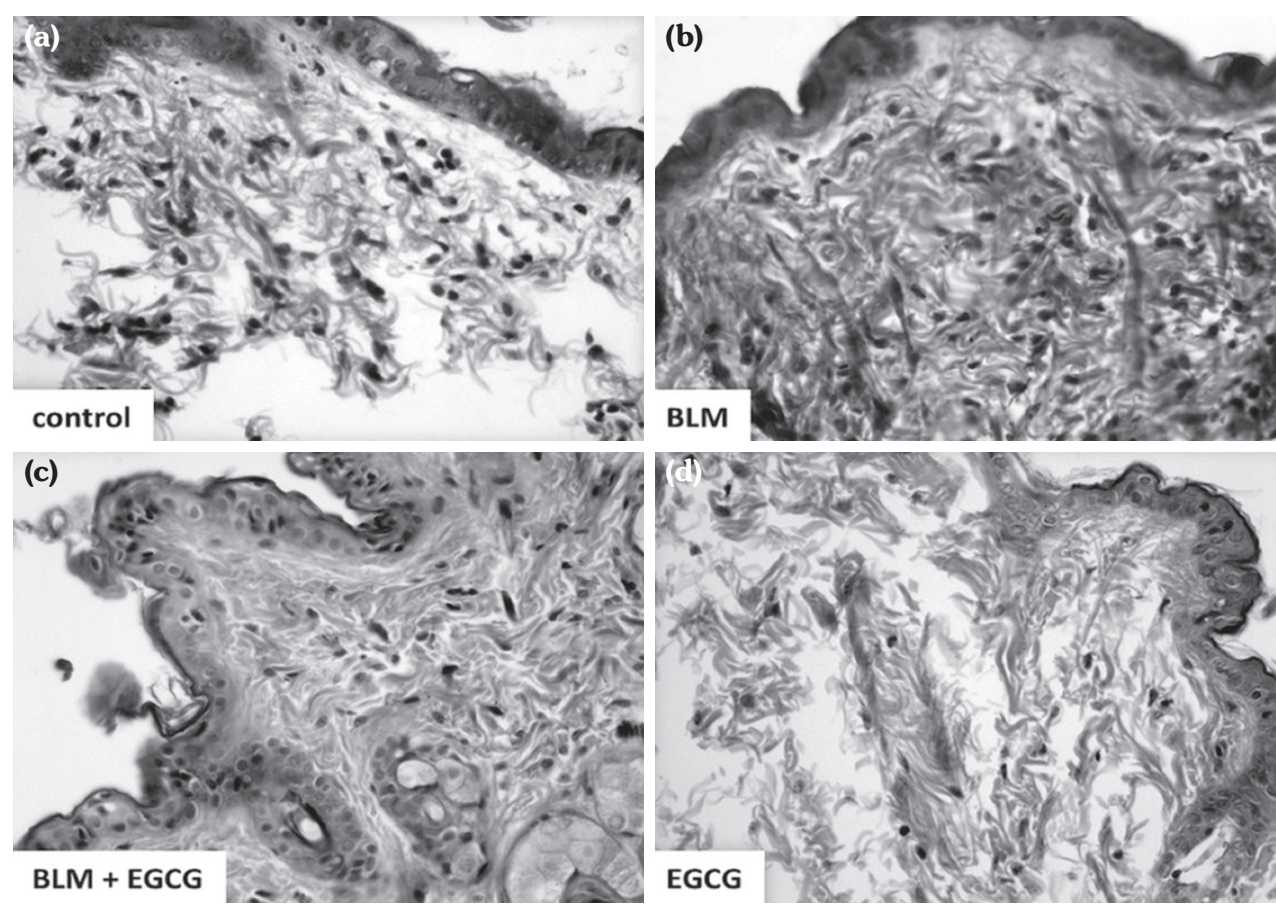

Figure 1. Masson's trichrome staining. Evidence of fibrosis (collagen content) was more prominent inbleomycingroup thanbleomycin + epigallocatechin-3-gallategroup. Original magnification $\times 20$.

(a) Control group, (b) bleomycin group, (c) bleomycin+epigallocatechin-3-gallate group,

(d) epigallocatechin-3-gallate group. BLM: Bleomycin; EGCG: Epigallocatechin-3-gallate.

\section{RESULTS}

Masson's trichrome staining was performed and the histological examination of the skin tissues from the mice is shown in Figure 1. The dermal thicknesses in the BLM + EGCG injected mice were significantly lower than in the BLM injected mice respectively ( $p<0.05$, Figure 1$)$.
The effect of EGCG on the activity of the SOD and MDA content is represented in Figure 2. A marked decrease in the SOD activity and a significant increase in the content of MDA were observed in the BLM groups compared with the controls. The MDA content was decreased and SOD activity was increased in the EGCG groups $(p<0.05)$ compared with the BLM groups.
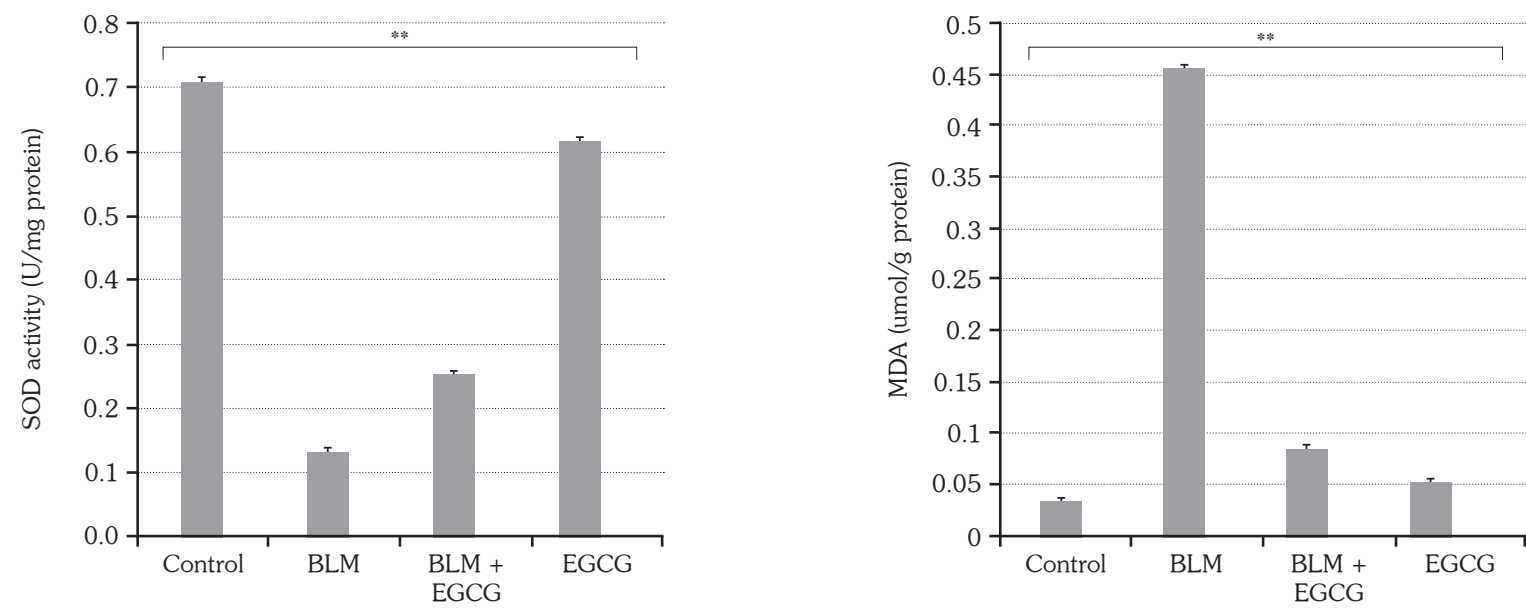

Figure 2. Epigallocatechin-3-gallate increased superoxide dismutase activity and decreased malondialdehyde activity (** $\left.{ }^{*}<0.05\right)$. SOD: Superoxide dismutase; BLM: Bleomycin; EGCG: Epigallocatechin-3-gallate; MDA: Malondialdehyde. 
(a)

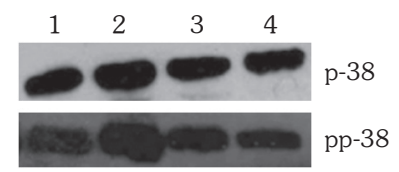

(b)

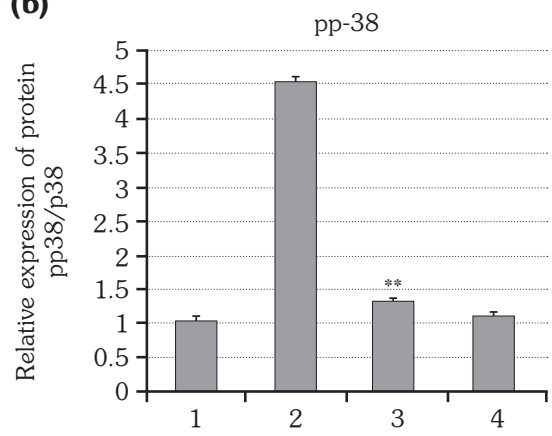

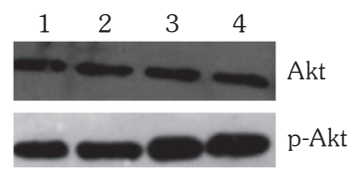

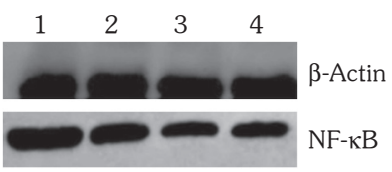

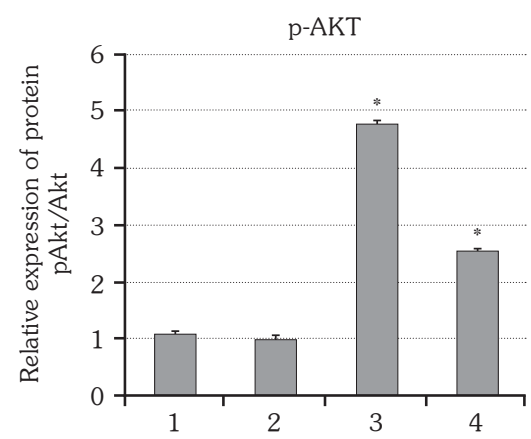

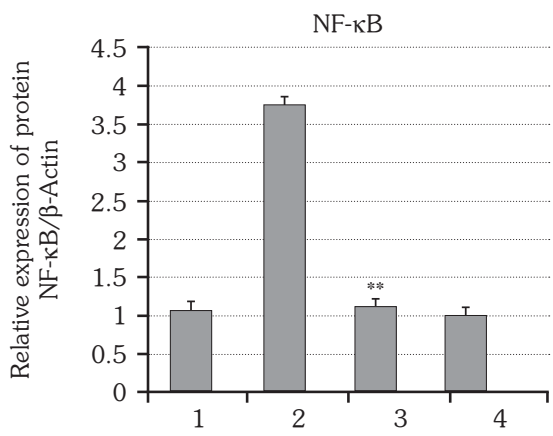

Figure 3. Effects of epigallocatechin-3-gallate treatment on p-Akt, pp-38 and nuclear factor-kB protein levels. (a) Western blotting were performed to measure protein levels of p-Akt, $\mathrm{pp}-38$ and nuclear factor- $\mathrm{kB}$, as described under materials and methods. (b) Quantitative results of p-Akt, pp-38 and nuclear factor- $\mathrm{kB}$ protein levels. Data are expressed as mean \pm standard deviation $(n=3)$. (1) Control group, (2) bleomycin group, (3) bleomycin + epigallocatechin-3-gallate group, (4) epigallocatechin-3-gallate group (" $\left.\mathrm{p}<0.05,{ }^{* *} \mathrm{p}<0.01\right)$. NF: Nuclear factor.

The western blotting analysis showed that EGCG increased the phosphorylation of Akt in the EGCG group compared with the control and BLM groups significantly (Figure 3, $\mathrm{p}<0.05$ ).

The pp-38 and NF- $\kappa \mathrm{B}$ protein levels did not differ between control, EGCG and BLM groups ( $>00.05)$. As shown in Figure 3, p-Akt protein levels increased in the BLM + EGCG group compared with the BLM group ( $p<0.05)$. Also, pp-38 and NF- $\kappa$ B protein levels decreased $(p<0.01)$ in the BLM+EGCG groups compared with the BLM groups.

\section{DISCUSSION}

In this study, the effect of EGCG on BLMinduced SSc mice model was evaluated, focusing on the oxidative stress pathways ( $\mathrm{p}-38, \mathrm{p}$-Akt and $\mathrm{NF}-\mathrm{kB}$ ) as well as the oxidative stress parameter MDA and the anti-oxidant enzyme SOD.

The p-38-mitogen-activated protein kinase (MAPK) pathway is conserved signaling pathway that responds to oxidative stress. ${ }^{40} \mathrm{NF}-\kappa \mathrm{B}$ signaling is also activated and it regulates cellular behavior. Also, PI3K/Akt pathway is considered as one of the most crucial factors for cell survival against oxidative stress. ${ }^{41}$
Scleroderma is a systemic autoimmune disease of unknown etiology and pathogenesis. It is characterized by progressive tissue fibrosis. Fibrosis, characterized by excessive accumulation of the extracellular matrix, is a clinical hallmark of many disorders such as SSc. Oxidative stress and tissue inflammation are the underlying events that accompany the development of fibrosis in SSc. ${ }^{4}$

A study investigated several dietary antioxidants in nature as therapeutic agents. ${ }^{42}$ and suggested that different antioxidants showed different defense mechanisms, and thus they possessed different potential therapeutic treatments. Authors reported that EGCG, one of the most active components of tea polyphenols, acts as antioxidant by scavenging reactive oxygen species. The significant antioxidant effect of EGCG is sweeping the free radicals. EGCG can act as electron traps to scavenge free radicals or inhibit the formation of ROS such as oxide and peroxynitrite. ${ }^{43}$ However, the authors did not study role of EGCG on the signaling pathways in SSc.

In our study, SOD activity was decreased and MDA content was increased in the experimental group (Figure 2). SOD enzyme activity and MDA levels are important indicators of oxidative stress and respond to induced oxidative stress. ${ }^{44}$ 
Epigallocatechin-3-gallate has also been shown by some studies to directly inhibit several molecular targets and regulate multiple signal transduction pathways such as MAPKs ( $p-38)$ and the redox-sensitive transcription factor (NF- $\mathrm{kB}$ ) in the cardiovascular and cancer studies. ${ }^{45-47}$ Akt signaling pathway plays an important role in cell growth, survival and motility. Several studies have also highlighted mechanisms by which EGCG could exert anti-fibrotic effects such as blocking the activation of NF- $\kappa B .{ }^{48,49} \mathrm{NF}-\kappa \mathrm{B}$ signaling pathway is activated by both oxidative stress and inflammatory factors and considered to be a prototypical pro-inflammatory signaling pathway for its role in the expression of other pro-inflammatory genes. ${ }^{50}$ Dooley et al. $^{51}$ and Kim et al. ${ }^{52}$ reported that EGCG reduces ROS, extracellular signal-regulated kinase $1 / 2$ and c-Jun $\mathrm{N}$-terminal kinase signaling pathways, as well as NF-KB activity. ${ }^{51,52}$

Our findings on the SSc mice model showed that Akt phosphorylation was increased in the experimental groups, and suggest that EGCG helps the survival of the cell (Figure 3). We also showed that EGCG could suppress phosphorylation of p-38 signaling and also decrease NF- $\kappa B$ activity of dermal tissue of mice (Figure 3). Moreover, we revealed that NF- $\mathrm{KB}$ phosphorylation decreased in the ECGC groups.

Our previous data indicated that EGCG can effectively inhibit collagen content and myofibroblasts and TNF beta signaling. ${ }^{53}$ In this study, we suggest that the inhibitory effect of EGCG on fibrosis may be at least partly due to ROS inhibition.

The present study has two limitations. Firstly, the hypothesis of the study could also be investigated by other oxidative stress marker experiments. Secondly, the hypothesis could be analyzed in another scleroderma experimental model.

In conclusion, we state that EGCG reduced the severity of fibrosis in an experimental animal model of SSc. The improved pathology occurred in association with lower concentrations of profibrogenic factors, lipid peroxides, Akt, p-38 and $\mathrm{NF}-\kappa \mathrm{B}$. This study presents novel data concerning the effect of EGCG on the oxidative state in a SSc model. In the future, these parameters may be investigated further for their possible role in the diagnosis and monitoring of SSc.

\section{Declaration of conflicting interests}

The authors declared no conflicts of interest with respect to the authorship and/or publication of this article.

\section{Funding}

The authors received no financial support for the research and/or authorship of this article.

\section{REFERENCES}

1. Varga J, Abraham D. Systemic sclerosis: a prototypic multisystem fibrotic disorder. Systemic sclerosis: a prototypic multisystem fibrotic disorder. J Clin Invest 2007; 117:557-67.

2. Bhattacharyya S, Wei J, Varga J. Understanding fibrosis in systemic sclerosis: shifting paradigms, emerging opportunities. Nat Rev Rheumatol 2011;8:42-54.

3. Hunzelmann N, Genth E, Krieg T, Lehmacher W, Melchers I, Meurer M, et al. The registry of the German Network for Systemic Scleroderma: frequency of disease subsets and patterns of organ involvement. Rheumatology (Oxford) 2008;47:1185-92.

4. Allanore Y, Dieude P, Boileau C. Genetic background of systemic sclerosis: autoimmune genes take centre stage. Rheumatology (Oxford) 2010;49:203-10.

5. Mayes MD, Lacey JV Jr, Beebe-Dimmer J, Gillespie BW, Cooper B, Laing TJ, et al. Prevalence, incidence, survival, and disease characteristics of systemic sclerosis in a large US population. Arthritis Rheum 2003;48:2246-55.

6. Herrick AL, Matucci Cerinic M. The emerging problem of oxidative stress and the role of antioxidants in systemic sclerosis. Clin Exp Rheumatol 2001;19:4-8.

7. Lundberg AC, Akesson A, Akesson B. Dietary intake and nutritional status in patients with systemic sclerosis. Ann Rheum Dis 1992;51:1143-8.

8. Servettaz A, Goulvestre C, Kavian N, Nicco C, Guilpain P, Chéreau C, et al. Selective oxidation of DNA topoisomerase 1 induces systemic sclerosis in the mouse. J Immunol 2009;182:5855-64.

9. Kawashiri SY, Ueki Y, Terada K, Yamasaki S, Aoyagi K, Kawakami A. Improvement of plasma endothelin-1 and nitric oxide in patients with systemic sclerosis by bosentan therapy. Rheumatol Int 2014;34:221-5.

10. Abou-Raya A, Abou-Raya S, Helmii M. Statins as immunomodulators in systemic sclerosis. Ann N Y Acad Sci 2007;1110:670-80.

11. Riccieri V, Spadaro A, Fuksa L, Firuzi O, Saso L, Valesini G. Specific oxidative stress parameters differently correlate with nailfold capillaroscopy changes and organ involvement in systemic sclerosis. Clin Rheumatol 2008;27:225-30. 
12. Ogawa F, Shimizu K, Muroi E, Hara T, Sato S. Increasing levels of serum antioxidant status, total antioxidant power, in systemic sclerosis. Clin Rheumatol 2011;30:921-5.

13. Umezawa H, Maeda K, Takeuchi T, Okami Y. New antibiotics, bleomycin A and B. J Antibiot (Tokyo) 1966;19:200-9.

14. Yamamoto T, Eckes B, Krieg T. Bleomycin increases steady-state levels of type I collagen, fibronectin and decorin mRNAs in human skin fibroblasts. Arch Dermatol Res 2000;292:556-61.

15. Clark JG, Starcher BC, Uitto J. Bleomycin-induced synthesis of type I procollagen by human lung and skin fibroblasts in culture. Biochim Biophys Acta 1980;631:359-70.

16. Yamamoto T, Kuroda M, Nishioka K. Animal model of sclerotic skin. III: Histopathological comparison of bleomycin-induced scleroderma in various mice strains. Arch Dermatol Res 2000;292:535-41.

17. Yamamoto T, Nishioka K. Animal model of sclerotic skin. IV: induction of dermal sclerosis by bleomycin is $\mathrm{T}$ cell independent. J Invest Dermatol 2001;117:999-1001.

18. Yamamoto T, Nishioka K. Animal model of sclerotic skin. V: Increased expression of alpha-smooth muscle actin in fibroblastic cells in bleomycin-induced scleroderma. Clin Immunol 2002;102:77-83.

19. Yamamoto $T$, Nishioka K. Animal model of sclerotic skin. VI: Evaluation of bleomycin-induced skin sclerosis in nude mice. Arch Dermatol Res 2004;295:453-6.

20. Yamamoto T, Takagawa S, Katayama I, Yamazaki $\mathrm{K}$, Hamazaki Y, Shinkai H, et al. Animal model of sclerotic skin. I: Local injections of bleomycin induce sclerotic skin mimicking scleroderma. J Invest Dermatol 1999;112:456-62.

21. Yamamoto T, Takahashi Y, Takagawa S, Katayama I, Nishioka K. Animal model of sclerotic skin. II. Bleomycin induced scleroderma in genetically mast cell deficient WBB6F1-W/W(V) mice. J Rheumatol 1999;26:2628-34.

22. Avouac J, Elhai M, Allanore Y. Experimental models of dermal fibrosis and systemic sclerosis. Joint Bone Spine 2013;80:23-8.

23. Rice-Evans CA, Miller NJ, Paganga G. Structureantioxidant activity relationships of flavonoids and phenolic acids. Free Radic Biol Med 1996;20:933-56.

24. Hu C, Kitts DD. Evaluation of antioxidant activity of epigallocatechin gallate in biphasic model systems in vitro. Mol Cell Biochem 2001;218:147-55.

25. Nakagawa H, Wachi M, Woo JT, Kato M, Kasai $\mathrm{S}$, Takahashi $\mathrm{F}$, et al. Fenton reaction is primarily involved in a mechanism of (-)-epigallocatechin-3gallate to induce osteoclastic cell death. Biochem Biophys Res Commun 2002;292:94-101.

26. Badea I, Taylor M, Rosenberg A, Foldvari M. Pathogenesis and therapeutic approaches for improved topical treatment in localized scleroderma and systemic sclerosis. Rheumatology (Oxford) 2009;48:213-21.

27. Gabrielli A, Svegliati S, Moroncini G, Amico D. New insights into the role of oxidative stress in scleroderma fibrosis. Open Rheumatol J 2012;6:87-95.

28. Distler JH, Jüngel A, Pileckyte M, Zwerina J, Michel BA, Gay RE, et al. Hypoxia-induced increase in the production of extracellular matrix proteins in systemic sclerosis. Arthritis Rheum 2007;56:4203-15.

29. Bozkurt M, Dag S, Oktayoglu P, Em S, Yuksel H, Caglayan M, et al. Serum prolidase enzyme activity and oxidative status in patients with scleroderma. Acta Medica Mediterranea 2014;30:127-32.

30. Gabrielli A, Svegliati S, Moroncini G, Pomponio G, Santillo M, Avvedimento EV. Oxidative stress and the pathogenesis of scleroderma: the Murrell's hypothesis revisited. Semin Immunopathol 2008;30:329-37.

31. Roh E, Kim JE, Kwon JY, Park JS, Bode AM, Dong Z, et al. Molecular mechanisms of green tea polyphenols with protective effects against skin photoaging. Crit Rev Food Sci Nutr 2017;57:1631-7.

32. OyetakinWhite $\mathrm{P}$, Tribout $\mathrm{H}$, Baron E. Protective mechanisms of green tea polyphenols in skin. Oxid Med Cell Longev 2012;2012:560682.

33. Santamarina AB, Carvalho-Silva M, Gomes LM, Okuda MH, Santana AA, Streck EL, et al. Decaffeinated green tea extract rich in epigallocatechin-3-gallate prevents fatty liver disease by increased activities of mitochondrial respiratory chain complexes in diet-induced obesity mice. J Nutr Biochem 2015;26:1348-56.

34. Imai K, Suga K, Nakachi K. Cancer-preventive effects of drinking green tea among a Japanese population. Prev Med 1997;26:769-75.

35. Shrubsole MJ, Lu W, Chen Z, Shu XO, Zheng Y, Dai $\mathrm{Q}$, et al. Drinking green tea modestly reduces breast cancer risk. J Nutr 2009;139:310-6.

36. Wu AH, Yu MC, Tseng CC, Hankin J, Pike MC. Green tea and risk of breast cancer in Asian Americans. Int $\mathrm{J}$ Cancer 2003;106:574-9.

37. Guo Y, Zhi F, Chen P, Zhao K, Xiang H, Mao Q, et al. Green tea and the risk of prostate cancer: A systematic review and meta-analysis. Medicine (Baltimore) 2017;96:6426.

38. Yamamoto T. Animal model of sclerotic skin induced by bleomycin: a clue to the pathogenesis of and therapy for scleroderma? Clin Immunol 2002;102:209-16.

39. Sriram N, Kalayarasan S, Sudhandiran G. Enhancement of antioxidant defense system by epigallocatechin-3-gallate during bleomycin induced experimental pulmonary fibrosis. Biol Pharm Bull 2008;31:1306-11.

40. Tian L, Chen J, Chen M, Gui C, Zhong CQ, Hong $\mathrm{L}$, et al. The p38 pathway regulates oxidative stress tolerance by phosphorylation of mitochondrial protein IscU. J Biol Chem 2014;289:31856-65. 
41. Liang Y, Li J, Lin Q, Huang P, Zhang L, Wu W, et al. Research Progress on Signaling Pathway-Associated Oxidative Stress in Endothelial Cells. Oxid Med Cell Longev 2017;2017:7156941.

42. Bruckdorfer KR. Antioxidants and CVD. Proc Nutr Soc 2008;67:214-22.

43. Tipoe GL, Leung TM, Hung MW, Fung ML. Green tea polyphenols as an anti-oxidant and anti-inflammatory agent for cardiovascular protection. Cardiovasc Hematol Disord Drug Targets 2007;7:135-44.

44. Del Rio D, Stewart AJ, Pellegrini N. A review of recent studies on malondialdehyde as toxic molecule and biological marker of oxidative stress. Nutr Metab Cardiovasc Dis 2005;15:316-28.

45. Khan N, Mukhtar H. Multitargeted therapy of cancer by green tea polyphenols. Cancer Lett 2008;269:269-80.

46. Stangl V, Dreger H, Stangl K, Lorenz M. Molecular targets of tea polyphenols in the cardiovascular system. Cardiovasc Res 2007;73:348-58.

47. Yang CS, Lambert JD, Hou Z, Ju J, Lu G, Hao X. Molecular targets for the cancer preventive activity of tea polyphenols. Mol Carcinog 2006;45:431-5.

48. Yasuda Y, Shimizu M, Sakai H, Iwasa J, Kubota M, Adachi S, et al. (-)-Epigallocatechin gallate prevents carbon tetrachloride-induced rat hepatic fibrosis by inhibiting the expression of the PDGFRbeta and IGF1R. Chem Biol Interact 2009;182:159-64.

49. Sakata R, Ueno T, Nakamura T, Sakamoto M, Torimura T, Sata M. Green tea polyphenol epigallocatechin-3gallate inhibits platelet-derived growth factor-induced proliferation of human hepatic stellate cell line LI90. J Hepatol 2004;40:52-9.

50. Sun SC. The non-canonical NF- $\kappa B$ pathway in immunity and inflammation. Nat Rev Immunol 2017;17:545-58.

51. Dooley A, Shi-Wen X, Aden N, Tranah T, Desai $\mathrm{N}$, Denton CP, et al. Modulation of collagen type I, fibronectin and dermal fibroblast function and activity, in systemic sclerosis by the antioxidant epigallocatechin3-gallate. Rheumatology (Oxford) 2010;49:2024-36.

52. Kim J, Hwang JS, Cho YK, Han Y, Jeon YJ, Yang KH. Protective effects of (-)-epigallocatechin-3-gallate on UVA- and UVB-induced skin damage. Skin Pharmacol Appl Skin Physiol 2001;14:11-9.

53. Kocak A, Harmancı D, Birlik M, Sarıŏlu S, Yılmaz $\mathrm{O}$, Cavdar Z, et al. Effects of epigallocatechin-3-gallate (EGCG) on a scleroderma model of fibrosis. Turk $\mathrm{J}$ Biochem 2018. [Access: February 8, 2018] 